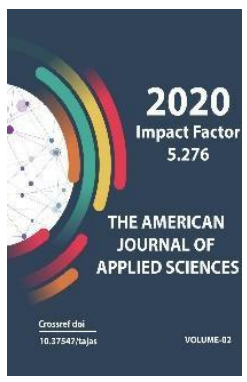

\title{
Goals And Objectives Of Teaching Reading Authentic Texts In A Modern Context
}

\author{
Djumabaeva Venera Tursinbaevna \\ English teacher at Karakalpak State University named after Berdakh, Uzbekistan.
}

\begin{abstract}
Journal Website:
http://usajournalshub.c

om/index,php/tajas

Copyright: Original content from this work may be used under the terms of the creative commons attributes

4.0 licence.
\end{abstract}

\section{ABSTRACT}

The article is devoted to one of the pressing problems in mastering a foreign language - learning to read authentic texts. Authentic texts are one of the sources of linguistic and regional knowledge. Accordingly, reading is a way of extracting information. No less acute is the problem of the definition of authentic text. The article presents various points on this issue.

\section{KEYWORDS}

Authentic text, reading, foreign language, language learning, criteria.

\section{INTRODUCTION}

Nowadays, when knowledge of a foreign language becomes more likely the norm, computer, economic and political terminology is based on a foreign language. At its core, communicative competence is integrative and consists of several components: communication skills in speaking, listening, reading and writing, linguistic knowledge and skills in this linguistic "building material" for generating and recognizing information.

Authentic texts are one of the important sources of obtaining linguistic and regional, regional geographic information for expanding the sociocultural background. Accordingly, the method of extracting information from texts for the most part is reading [2,18-21].

When learning languages, reading is generally understood as an understanding of the written text in a foreign language. Thus, the reading is a passive ability.

Reading is a receptive form of speech activity associated with the cure of information 
through the visual channel. This type of speech activity is based on skills related to the extraction of incoming information.

In the process of teaching foreign languages, reading performs two functions:

- Reading is the purpose of learning is a type of speech activity (means of extracting information);

- Reading is a means of teaching other types of speech activity. But in order to become a means, reading must become a goal, for any means must be mastered well.

\section{MATERIALS AND METHODS}

The mature ability to read involves both the possession of all types of reading and the ease of transition from one type to another, depending on the change in the purpose of obtaining information from a given text.

Types of reading:

1. According to the target area of activity orientation, viewing, studying, search.

2. In form - to himself, individual, choral, loud.

3. By the method of disclosing the content analytical, synthetic, translated, nontranslated.

4. At the place of reading - home reading, classroom reading .

5. By the nature of the organization of activity - prepared, unprepared, training, control.

Depending on the target installation, there are distinguished viewing, familiarization, studying and search reading.

View reading involves getting a general idea of the material being read. Its purpose is to obtain the most general idea of the topic and range of issues addressed in the text. Such a reading takes place upon first acquaintance with the content of a new publication in order to determine whether it contains information of interest to the reader, and on this basis decide whether to read it or not. It can also end with the presentation of the results read in the form of a message or abstract. For teaching reading, it is necessary to select a number of thematic related test materials and create viewing situations. The speed of viewing reading should not be lower than 500 words per minute, and training tasks should be aimed at developing skills and orientation in the logical - semantic structure of the text, the ability to extract and use the source text material in accordance with a specific communicative task.

Introductory reading ( reading for the main idea ) is a cognitive reading, in which the subject of attention of the reader becomes the entire speech work (book, story) without setting to receive certain information. This is a reading "for oneself", without preliminary special installation for subsequent use or reproduction of the received information. The main communicative task facing the reader is to quickly extract the entire text to extract the information contained in it, i.e. find out what issues and how are resolved in the text, what exactly does it say on these issues.

The topic of the fact-finding reading should not be lower than 180 words per minute. For practice, this type of reading uses relatively long texts that are easy in language terms, containing at least $25-30 \%$ of redundant, secondary information.

Learning reading ( detail reading ) provides the most complete and accurate understanding of all the information contained in the text and its critical reflection. The object of "study" in this type of reading is the information contained in the text. His task is also the formation of the learner's ability to independently overcome difficulties in understanding a foreign text .

The pace of learning reading is 50 to 60 words per minute. For this type of reading, texts are 
selected that have cognitive value, informative value and are of the greatest difficulty for this stage of training, both in content and in language terms.

In classes in a foreign language, all types of reading are taught:

- Reading with a general coverage of the content (viewing, fact-finding);

- Reading for the purpose of a detailed understanding of what has been read (learning);

- Reading in order to extract specific information (search) [3,19].

Authentic text ( from the Greek. Authentikos genuine), a text corresponding in content to a text in another language and having the same strength with us.

\section{RESULT AND DISCUSSION}

These texts teach you how to rationally extract specific factual information at the level of values. The objectives pursued by the teacher and student reading authentic text are as follows:

- learn a language at a deeper level of meanings;

- strengthen the motivation for learning a language, as natural human communication takes place at the level of meanings (correspondence with native speakers);

- emotionally, personally engage students in the reading process, and this is a prerequisite for including mechanisms for generating initiative speech - speaking and writing;

- identify and recognize intercultural differences.

The problem of authentic materials used in teaching foreign languages causes a lot of controversy in itself.

The very concept of authentic materials appeared in the methodology not so long ago, which is associated with the modern setting of the goals of teaching a foreign language.

Currently, several approaches have been singled out to determine the essence of authentic materials $[3,20]$.

Some researchers, for example, Krichevskaya

K.S. authentic materials are defined as genuine literary, visual, objects of real activity, such as clothes, furniture, dishes, and their illustrative images.

K.S. Krichevskaya identifies everyday life materials as an independent group of pragmatic materials (announcements, questionnaires, signboards, labels, menus and accounts, etc.), which, in terms of accessibility and everyday nature of use, seem quite significant to create an illusion of familiarization with the environment native speakers and believes that their role is an order of magnitude higher than authentic texts from the textbook, although they can be inferior to them in volume [1,13].

There are options for an authentic study text. They consider a set of structural features of such a text that meets the standards adopted by native speakers. According to them, such a text is an authentic discourse (a text taken in the event aspect), which is characterized by the naturalness of lexical content and grammatical forms, situational adequacy of the used language means, illustrates cases of authentic usage.

Authors include authentic materials: personal letters, jokes, articles, recipes, interviews, popular science and country texts.

Thus, authentic materials are materials taken from original sources, which are characterized by the naturalness of lexical content and grammatical forms, the situational adequacy of the language means used, illustrates cases of authentic usage, and which, although not intended specifically for educational purposes, 
can be used when teaching a foreign language.

Educational - authentic materials are materials specially developed taking into account all the parameters of an authentic educational process and criteria of authenticity and intended to expand specific educational tasks.

The main criteria of authenticity is the criterion of functionality. Functionality is understood as the orientation of authentic materials to life use, to create the illusion of familiarization with the natural language environment, which is the main factor in the successful mastery of a foreign language. Work on functionally authentic material brings the student closer to the real conditions of language use, introduces him to a variety of linguistic means and prepares them for independent authentic use of these means in speech $[2,68]$.

\section{CONCLUSION}

Summing up, it is necessary to emphasize that teaching a natural, modern foreign language is possible only on condition of using materials taken from the life of native speakers or compiled taking into account the peculiarities of their culture and mentality in accordance with accepted and used speech norms. The use of such authentic and educational authentic materials representing a natural speech product created for methodological purposes will allow more effective teaching of all types of speech activity.

\section{REFERENCES}

1. Baryshnikov N. V. Methods of teaching a second foreign language at school. Moscow: Education, 2003.

2. Galskova N. D. Modern methods of teaching foreign languages. Manual for teachers. Moscow: ARKTI, 2000.
3. Krichevskaya, K. S. Pragmatic materials that introduce students to the culture and environment of the inhabitants of the country of the studied language / / IYASH. 1996. № 1. p. 13-17.

4. Salanovich, N. A. Teaching to read authentic texts of linguistic and country studies content / / Foreign language in school. 1999. p. 18-21.

5. Salanovich N. A. Teaching to read authentic texts of linguistic and cultural content // Foreign languages at school. 1991. № 1.

6. Solovova, E, N. Practical training for the basic course of foreign language teaching methods: Textbook.manual for universities. - M.: Education. 2004. - p. 192

7. Solovova E. N. Methods of teaching foreign languages: Basic course of lectures. Moscow: Education, 2002. 